\title{
Breaking up Sedentary Time in Overweight/Obese Adults on Work Days and Non-Work Days: Results from a Feasibility Study
}

\author{
Nathan P. De Jong 1이 Isaac Debache ${ }^{2,3}$, Zhaoxing Pan ${ }^{4}$, Mael Garnotel ${ }^{5,6}$, Kate Lyden ${ }^{7}$, \\ Cédric Sueur 2,3, Chantal Simon ${ }^{6,7}$ (1) , Daniel H. Bessesen ${ }^{1,8,+}$ and Audrey Bergouignan $1,2,3, *,+$ (i) \\ 1 Division of Endocrinology, Metabolism, and Diabetes and Anschutz Health and Wellness Center, \\ University of Colorado, School of Medicine, Aurora, CO 80045, USA; \\ nathan.dejong@ucdenver.edu (N.P.D.J.); daniel.bessesen@ucdenver.edu (D.H.B.) \\ 2 Institut Pluridisciplinaire Hubert Curien, Université de Strasbourg, CNRS 67000 Strasbourg, France; \\ isaac.debache@iphc.cnrs.fr (I.D.); Cedric.sueur@iphc.cnrs.fr (C.S.) \\ 3 UMR 7178 Centre National de la Recherche scientifique (CNRS), 67000 Strasbourg, France \\ 4 Department of Biostatistics and Informatics, Anschutz Medical Campus, University of Colorado, \\ Aurora, CO 80045, USA; zhaoxing.pan@ucdenver.edu \\ 5 CARMEN, CRNH, INSERM U1060/University of Lyon 1/INRA U1235 Lyon, France; \\ ext-mael.garnotel@chu-lyon.fr \\ 6 Laboratoire de Biochimie CHLS 69310 Pierre Bénite, France; chantal@simon-bertrand.com \\ 7 KAL Research and Consulting LLC, Denver, CO 80002, USA; katelyden6@gmail.com \\ 8 Denver Health Medical Center, Denver, CO 80204, USA \\ * Correspondence: Audrey.bergouignan@iphc.cnrs.fr; Tel.: +33-388-1069-14 \\ + These authors contributed equally to this work.
}

Received: 31 August 2018; Accepted: 14 November 2018; Published: 16 November 2018

\begin{abstract}
Office workers are vulnerable to the adverse health effects of sedentary behavior (i.e., sitting time). Increasing physical activity and preventing time spent sitting is an occupational health priority. This randomized crossover design study compared the short-term (3-days) effects of hourly interruptions of sedentary time with 5-min micrrobouts of activity for 9 hours (MICRO) to a sedentary control condition (SED) and a duration-matched continuous single bout of physical activity ( $45-\mathrm{min} / \mathrm{d}$, ONE) condition on inclinometer-derived sitting-time on work and non-work days in sedentary overweight/obese adults. Differences in sitting/lying, standing, stepping, number of sit/stand transitions, time spent in moderate and vigorous activity (MVPA), energy expenditure, self-perceived vigor and fatigue, and insulin sensitivity were also examined. Twenty-two participants (10M/12F; $31.7 \pm 1.3$ year old BMI $30.4 \pm 0.5 \mathrm{~kg} / \mathrm{m}^{2}$ ) completed all conditions. No between-condition effects were observed in sitting-time and sit/stand transitions. Both interventions increased daily steps, MVPA and energy expenditure with increases being greater in ONE than MICRO. Feelings of vigor and fasting insulin sensitivity were also improved. Participants reported less fatigue with MICRO than SED and ONE. Both interventions increase physical activity and energy expenditure in occupational and leisure-time contexts. The sustainability of these effects over the long term and on health outcomes will need to be tested in future studies.
\end{abstract}

Keywords: sedentary behaviors; sitting; microbouts; physical activity; MVPA; activity energy expenditure; vigor; fatigue; insulin sensitivity

NCT\# NCT02258438 


\section{Introduction}

Sedentary behavior, i.e., sitting time, has been associated with adverse health outcomes including body mass index, cardio-metabolic outcomes, mental health and premature mortality [1-9] and has emerged as an important public health concern [10]. In addition to total daily sitting time, prolonged unbroken sitting time has been negatively associated with cardiometabolic health biomarkers [11,12].

Over the past few decades, advances in technology and computer-based tasks have increased time spent sitting at the workplace [13]. It has been found that office-based employees spend $66 \%$ of their total work time sitting with $25 \%$ of total sitting time in bouts longer than 55 min [14]. These changes in the workplace have been associated with reduced daily occupational energy expenditure. Since the 1960s, in the USA and the UK, population levels of occupational physical activity have declined by more than 30\% [15]. Facing this developing public health challenge, the World Health Organization has recently published new guidelines for employers to promote healthier occupational environments [16]. Among the four major components of the guidelines, limiting prolonged sitting and increasing physical activity is one of them. While guidelines exist, they still need to be translated into practical strategies that can be implemented on a large scale. In this context, there has been increasing interest in understanding the efficacy of a broad range of interventions targeting sedentary behavior in the workplace.

A growing number of studies have examined environmental changes in the occupational setting to reduce sitting time such as active workstations and include sit-to-stand desks, treadmill desks and seated active workstations utilizing portable pedal machines [17-19]. These interventions have shown mixed results. While individual sit-to-stand desk interventions have not been shown to decrease sedentary time [20], interventions with multi-level components targeting the individual but also the social and built environment showed that stand-up desk options reduce sitting and increase standing time [21]. However, no effect on stepping time was observed. A personalized consultation with weekly emails that aimed to reduce prolonged sitting time did not decrease total daily sedentary time but reduced the occurrence of sedentary bouts of more than $30 \mathrm{~min}$ [22,23]. Another study using hourly computer screen prompts and text messages to break up sitting decreased total time spent sitting and increased the number of daily steps, but failed at increasing the number of sit-to-stand transitions [10]. Another goal of these interventions is to increase energy expenditure. The implementation of treadmill desks and seated active workstations can reduce daily sitting time, increase time spent in physical activity [24,25] and almost triple the energy expenditure of that measured while sitting. For example, walking at $1.8 \mathrm{~km} / \mathrm{h}$ can induce an expenditure above $0.41 \mathrm{MJ} / \mathrm{h}$, which could beneficially impact energy balance if sustained for several hours per day [26,27]. However, long-term adherence to these interventions (12 months) are poor [24,25], treadmill desks are costly and present a safety hazard. Therefore, a cost effective, easy to implement intervention that can reduce total time spent sitting, prevent prolonged sitting bouts as well as increase time spent active and energy expenditure is still needed. Implementing frequent short bursts of walking could fulfill these requirements.

Such interventions have already been tested in the laboratory setting. Past studies showed beneficial effects of frequent interruptions of sitting time with short bouts of activity varying in mode, frequency, duration and intensity on metabolic, cognitive and hemodynamic outcomes [28-40]. Regardless of adiposity, sex and age frequent interruptions of sedentary actives with walking breaks have been associated with attenuated postprandial plasma glucose and insulin concentrations in obese and type 2 diabetic adults [31-40]. We have shown that interrupting sedentary behavior with short bursts of treadmill walking increases self-perceived feelings of energy, vigor and mood and decreases feelings of fatigue throughout the day in normal weight adults [30]. The effect of such an intervention on the profile of physical activity and energy expenditure in free-living conditions is unknown.

While the workplace has been identified as a priority setting for addressing sedentary behaviors, it may be important to target sedentary behaviors in other contexts such as on non-working days. Non-working days also comprise a large portion of a working adult's week and have also been associated with a large amount of time attributed to sedentary activities [41]. Because workers who 
spend more time in sedentary pursuits during work hours do not compensate by being more active in non-working periods [20], there is a need to test interventions that aim at reducing time spent sedentary both during work days and non-work days outside of the controlled laboratory environment.

Based on the data generated by the past intervention studies conducted in the laboratory setting and the real-world, we hypothesized that an intervention aimed at breaking up sedentary time with short bouts of activity could attenuate time spent sitting, increase daily physical activity and energy expenditure, and positively impact metabolic health and well-being in office workers. The purpose of this study was to test the feasibility to implement such an intervention over a short period of time (3-days) in the daily life of overweight sedentary male and female adults during work days and non-work days. To test whether the effects on time spent sitting, time spent physically active and energy expenditure were due to the frequent interruptions of sedentary time with short bouts of activity or to the total time spent active, we used a three arm cross-over randomized design. Frequent interruptions of sedentary time with short bouts of physical activity were compared to a duration-matched single continuous bout of physical activity, and a sedentary control condition. Further, we compared the effect of the interventions on self-perceived vigor and fatigue and an index of insulin sensitivity. Finally, we assessed how difficult it was for participants to implement these interventions in their daily life on work days and non-work days.

\section{Methods}

\subsection{Participants}

This study was approved by the Colorado Multiple Institutional Review Board (COMIRB) and was in accordance with the Declaration of Helsinki (COMIRB\# 14-0429). Eligible participants were between 19-45 years old with an occupation that requires sitting time, had a body mass index (BMI) between $27-33 \mathrm{~kg} / \mathrm{m}^{2}$, were weight stable for at least 3 months, insulin sensitive (fasting plasma insulin concentration below $25 \mu \mathrm{IU} / \mathrm{mL}$ ), and self-reporting $>6 \mathrm{~h} /$ day of occupational sitting. All women enrolled in the study were pre-menopausal and could use birth control medications. Exclusion criteria included clinically diagnosed diabetes, taking glucose- and/or lipid-lowering medications, dyslipidemia, smoking, or meeting the American College of Sports Medicine (ACSM) physical activity recommendations (>150 min/week MVPA). Participants were recruited between October 2014 and October 2016 from newspaper advertisements, public announcements, and flyers in the Denver and Aurora areas in Colorado, USA. Participants were randomized to one of three possible trial-condition orders using balanced blocks separately prepared for male and female participants. The study statistician (Z.P.) prepared the computer-generated randomization lists and sealed envelopes for randomization [42].

\subsection{Study Design}

Eligible volunteers completed three separate 3-day trial phases under free-living conditions. The study phases were separated by a 28-day wash out period and women were all studied in the follicular phase of their menstrual cycle. All the study related visits were conducted at the Clinical and Translational Research Center of University of Colorado (CTRC). The three trial conditions were administered in random order:

Sedentary (SED): Free-living subjects maintained their usual levels of daily activity during the three days of measurement and were asked to refrain from structured exercise.

Sedentary +1 continuous bout of activity (ONE): During the 3-days of measurement, subjects were asked to perform 45-min of moderate-intensity walking once per day and maintain their usual sedentary lifestyle the rest of the day.

Sedentary + microbouts of activity (MICRO): During the 3-days of measurement, participants were asked to perform a 5-min bout of moderate-intensity walking bout each hour for 9 consecutive hours throughout the day and maintain their usual sedentary lifestyle the rest of the time. 
For both interventions, the intensity of the activity was defined during the screening visit. On each day of measurement, participants were asked to complete a diary log and record the time the participant went to sleep and woke up from sleep, the time the bouts of physical activity were performed and if it was a work day or not.

\subsection{Screening Visit}

Subjects were screened, consented and underwent a review of medical history and physical examination and a blood draw to verify fasting plasma insulin concentrations for eligibility. Resting Metabolic Rate (RMR) was measured by indirect calorimetry for $30 \mathrm{~min}$ in the fasted state, under resting conditions and at thermoneutrality. Body composition including fat-free mass (FFM) and fat mass (FM) was measured by dual energy X-ray absorptiometry (DXA, Hologic Delphi-W, Bedford, MA, USA). The short version of the International Physical Activity Questionnaire (IPAQ) was completed to assess habitual physical activity and time spent sitting [43]. Subjects then performed an incremental exercise test on a treadmill (increments of $0.3 \mathrm{miles} / \mathrm{h}$ every 2-min) to determine a walking pace that was then prescribed for ONE and MICRO conditions. For each exercise level, subjects rated their perceived effort on a Borg scale from 0 (very light) to 20 (maximal exertion). The aim was to identify the walking speed that subjects associated with a perceived exertion level of 13 (somewhat hard). Subjects were instructed to walk at this pace for each bout of activity during the intervention.

\subsection{Measurement of Time Spent Sitting/Lying, Standing, Stepping and Daily Steps}

Time spent sitting/lying, standing, stepping and daily steps were quantified using an ActivPALTM triaxial accelerometer/inclinometer (PAL Technologies Ltd., Glasgow, Scotland) during the three days of measurement in each condition. Participants were instructed to wear the monitor at all times. The device was worn midline on the anterior aspect of the thigh and wrapped with a nitrile sleeve, allowing for $24 \mathrm{~h}$ measurement. The monitor produces a signal related to thigh inclination and is a valid and reliable measurement tool for determining posture and motion during activities of daily living [44]. When the monitor is oriented horizontally, it classifies the activity as sitting/lying. Vertical positioning of the monitor is classified as standing. Step cadence and number of steps were recorded by the monitor when a participant was walking.

The ActivPAL ${ }^{\mathrm{TM}}$ has been validated for use in adults to distinguish between sitting/lying, standing, and stepping activities [44-47]. Data event files from the ActivPAL ${ }^{\mathrm{TM}}$ were used to quantify sitting/lying, standing, and stepping time. In these files, the ActivPAL ${ }^{\mathrm{TM}}$ records each time an activity changes and the time that the activity changed. Sitting/lying, standing, and stepping time were calculated by summing the duration of each event and the number of breaks from sitting time were quantified as a transition from sitting/lying to either standing or stepping. Sitting bouts lasting longer than 30-min and 60-min were also used to test the effect of the conditions on the sitting bout length. A customized R program (www.r-project.org) was used to convert the event data file to a second-by-second data file to estimate additional metrics of sedentary behaviors and time spent sitting/lying, standing, stepping. The following metrics of sedentary behaviors were computed over $24 \mathrm{~h}$ : total sedentary time (total time spent in sitting/lying events), total breaks in sedentary time (number of times a sitting/lying event was followed by a standing or stepping event), and time (minutes/day) in sedentary bouts $\geq 30$ and $\geq 60-\mathrm{min}$. The same outcomes were also reported as percentage of waking time. Because sleep time was removed, we assumed that sitting/lying time mainly corresponded to sitting time during waking hours. The $\mathrm{R}$ package (PAactivPAL) is available for researchers to generate these metrics [48].

\subsection{Measurement of Physical Activity Intensity, Activity Energy Expenditure and Physical Activity Level}

Activity energy expenditure (AEE) and time spent in different activity intensities were determined using the ActiGraph GT3X tri-axial accelerometer (ActiGraph, Pensacola, FL, USA). Participants were instructed to wear the accelerometer during wake time by attaching it to their right hip directly 
above their right knee using an elastic belt that was provided. A sampling rate of $30-\mathrm{Hz}$ was used. After each of the 3-day study conditions, data were downloaded using the Actilife 6.13 software provided by the manufacturer and AEE per minute $(\mathrm{J} / \mathrm{kg} / \mathrm{min})$ was estimated using the 'Freedson vector magnitude combination model' $[49,50]$. Total energy expenditure (MJ/d) was calculated as $(\mathrm{AEE}+\mathrm{RMR}) / 0.9$, where RMR was resting metabolic rate (MJ/d). Physical activity level (PAL) was calculated as the ratio between TEE over measured RMR. Cut-points of $<1.5$ and $<3$ METs and $>3$ METs (metabolic equivalents) were used for very light intensity activity, light intensity activity and moderate-to-very vigorous activity, respectively. Minute-data during waking hours were summed to obtain data per day. Although sedentary behavior has been defined as activities with an energy expenditure below 1.5 METs while in a sitting, reclining or lying posture [51], activities with METs $<1.5$ were referred to as very light intensity activity in our study. By only measuring energy expenditure without recognition of the concomitant posture, we are including activities such as standing that are not sedentary activities. By choosing the term "very light intensity activity" we are more conservative and avoiding any misinterpretation.

\subsection{Perception of the Challenges Associated with the Conditions, Self-Perceived Vigor and Fatigue}

At the end of each intervention or control day participants filled out online $100 \mathrm{~mm}$ visual analog scales (VAS) designed to capture their perception of the study condition [52]. The VAS addressed the following question "Please indicate on the scale how challenging you found the day." The anchors for this question were "Extremely Easy" and "Extremely Challenging." Immediately after the first survey, participants then completed an online modified version of the Perception of Mood survey (POMs) to assess changes in feelings of vigor and fatigue [53]. Only the POMs-Fatigue (POMs-F; $n=7$ items) and the POMs-Vigor (POMs-V; $n=8$ items) subscales were used for analysis.

\subsection{Plasma Metabolic Outcomes}

The morning after each 3-day trial, the participants reported to the CTRC for a fasting blood collection which was analyzed for glucose and insulin. Whole blood was added to a preservative (3.6 mg EDTA plus $2.4 \mathrm{mg}$ glutathione in distilled water). Insulin concentrations were measured using a standard double antibody radioimmunoassay (EMD Millipore, St. Charles, MO, USA). Serum glucose concentrations were determined using the hexokinase method (Wako Diagnostics, Mountain View, CA, USA). These analyses were performed on the Beckman Coulter AU480 Chemistry Analyzer (Brea, CA, USA).

\subsection{Statistical Analysis}

Based on the diary log information, data were recorded on 43,47 and 43 work days while in SED, ONE and MICRO conditions, respectively. Consequently, 23, 19 and 23 study days were non-work days when participants were in SED, ONE and MICRO conditions, respectively. The analysis of the working status effect (work day versus non-work day) was a posteriori analysis. This is why the number of work days and non-work days are unbalanced across the three conditions and the work status.

If there was more than one measure assessed at different days per condition and work status, the mean value of the repeated measures served as outcome in the model. Linear mixed models were used to test differences in the two activity monitor outcomes, self-perceived challenge, vigor and fatigue, with sequence, period, condition (SED, MICRO and ONE), work status (work day vs. non-work day) and condition-by-work status interaction as fixed effects and subjects as random effect with a compound symmetry covariance. Contrasts were used, under this model, to test for the between work status difference under each condition, the between condition differences separately on workdays and non-work days and the between work status difference with respect to the between condition difference. No correction for multiple comparisons was applied. Fasting plasma insulin and glucose concentrations measured on the morning of day 4 were also analyzed using linear mixed model but work status was not considered. Indeed, within the three days prior to the blood draw, days could have 
been randomly spent at work or not, it was therefore impossible to know if the interaction between the condition and the work status had any influence on index of insulin sensitivity. Data are expressed as mean $\pm \mathrm{SD}$, unless otherwise stated. All statistical analyses were performed with SAS 9.4 (SAS Institute, Cary, NC, USA).

\section{Results}

\subsection{Subjects' Characteristics and Compliance with the Interventions}

Subjects' characteristics are displayed on Table 1. On average over the 3-days of intervention, participants performed $97.6 \pm 0.0 \%$ and $98.4 \pm 0.1 \%$ of the prescribed physical activity bouts in MICRO and ONE, respectively. High levels of compliance with both interventions was attained despite reporting that performing the physical activity interventions was more challenging than spending a day being sedentary (Intervention effect: $p=0.007$; Figure 1). While participants reported that MICRO was challenging to perform on work days ( $p=0.004$ vs. SED), ONE was perceived to be more challenging to comply with on non-work days compared to both SED $(p=0.05)$ and MICRO $(p=0.04)$.

Table 1. Study participant's anthropological characteristics and habitual sitting time.

\begin{tabular}{cccc}
\hline Parameters & Males & Females & All \\
\hline$n$ & 10 & 12 & 22 \\
Age $($ year $)$ & $31.5 \pm 7.4$ & $32.0 \pm 6.1$ & $31.8 \pm 6.6$ \\
BMI $\left(\mathrm{kg} / \mathrm{m}^{2}\right)$ & $28.8 \pm 2.9$ & $31.7 \pm 1.8$ & $30.5 \pm 2.7$ \\
FM $(\mathrm{kg})$ & $24.6 \pm 4.3^{* * *}$ & $36.0 \pm 4.7$ & $30.9 \pm 7.3$ \\
FFM $(\mathrm{kg})$ & $63.1 \pm 9.9^{* * *}$ & $49.9 \pm 5.0$ & $56.0 \pm 10.1$ \\
FM $(\%)$ & $28.1 \pm 2.4^{* * *}$ & $41.8 \pm 2.4$ & $35.6 \pm 7.4$ \\
Self-reported sitting time $(\mathrm{h} / \mathrm{d})$ & $9.0 \pm 3.2$ & $10.6 \pm 1.1$ & $9.5 \pm 4.1$ \\
\hline
\end{tabular}

Data are presented as mean $\pm \mathrm{SD} .{ }^{* * *} p<0.0001$ vs. Female. $n$, number of subjects; BMI, body mass index; FFM, fat-free mass; FM, fat mass; Self-reported sitting time was estimated from the IPAQ, international physical activity questionnaire.
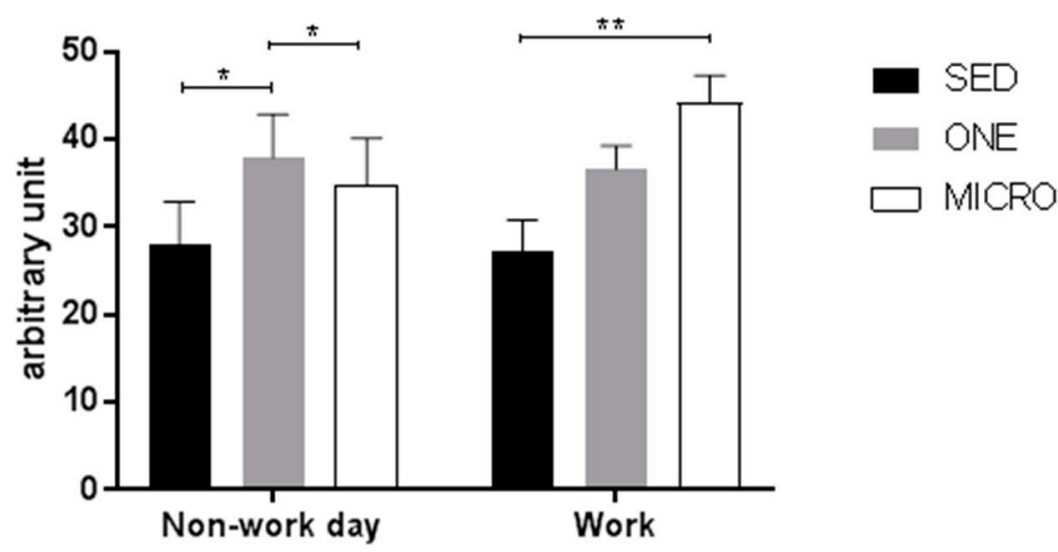

Figure 1. Visual analog scale representing the perception of the challenges associated with the conditions. At the end of each intervention or control day participants filled out online $100 \mathrm{~mm}$ visual analog scales (VAS) designed to capture their perception of the study condition. The VAS addressed the following question "Please indicate on the scale how challenging you found the day." The anchors for this question were "Extremely Easy" and "Extremely Challenging." SED, indicates the sedentary condition; ONE, indicates the one-bout intervention; $\mathrm{MICRO}$, indicates the microbouts intervention. ${ }^{*} p<0.05,{ }^{* *} p<0.01$ vs. sedentary control. 


\subsection{Effect of the Physical Activity Interventions on Time Spent Sitting/Lying, Standing and Stepping}

Time spent sitting/lying, standing and stepping over $24 \mathrm{~h}$ is reported in Table 2. One ActivPAL ${ }^{\mathrm{TM}}$ was lost and two were defective, we are therefore reporting data obtained in 19 subjects. Both MICRO (11. $4 \pm 4.7$ vs. $9.2 \pm 3.4 \%, p=0.009)$ and ONE $(13.9 \pm 3.5 \%$ vs. $9.2 \pm 3.4 \%, p<0.0001)$ increased the percentage of waking time spent stepping compared to SED on work days but not on non-work days. This resulted in $0.4 \pm 0.1 \mathrm{~h}$ more spent stepping in ONE than in MICRO $(p=0.01)$. As a result, the number of daily steps increased from $7125 \pm 2554$ to $12,257 \pm 3145$ in ONE $(p<0.0001)$ and $10,036 \pm 4262$ in MICRO $(p=0.0002)$ on work days; participants took more steps when performing ONE than MICRO $(p=0.005)$. Both ONE $(+2967 \pm 456, p=0.005)$ and MICRO $(+2841 \pm 552, p=0.02)$ led to a greater number of daily steps compared to SED on non-working days. However, time spent sitting and standing, the average duration of the sedentary bouts and the number of transitions from the sitting to standing position (index of breaking up prolonged sitting) were not significantly different across conditions and days ( $p>0.05$ for all). Surprisingly, the sitting bouts of more than $30 \mathrm{~min}$ tended to occur more often in MICRO than in both SED $(p=0.057)$ and ONE $(p=0.051)$ when in leisure contexts.

Table 2. Time spent sitting/lying, standing and stepping over $24 \mathrm{hr}$ and as percent of wake time.

\begin{tabular}{|c|c|c|c|c|c|c|}
\hline \multirow[t]{2}{*}{$\begin{array}{c}\text { Physical Activity } \\
\text { Outcomes }\end{array}$} & \multicolumn{2}{|c|}{ SED } & \multicolumn{2}{|c|}{ ONE } & \multicolumn{2}{|c|}{ MICRO } \\
\hline & Non-work day & Work & Non-work day & Work & Non-work day & Work \\
\hline Sitting/lying (h/d) & $9.8 \pm 2.0$ & $10.6 \pm 2.3$ & $9.6 \pm 1.9$ & $10.2 \pm 2.4$ & $9.6 \pm 2.5$ & $10.5 \pm 2.2$ \\
\hline Stepping $(\mathrm{h} / \mathrm{d})$ & $1.4 \pm 0.5$ & $1.4 \pm 0.5$ & $1.7 \pm 0.4$ & $2.1 \pm 0.5^{* * *}$ & $1.7 \pm 0.4$ & $1.7 \pm 0.7 * * \delta$ \\
\hline Sitting (\% waking time) & $66.6 \pm 14.2$ & $68.4 \pm 13.5$ & $67.2 \pm 12.7$ & $64.5 \pm 10.4$ & $64.0 \pm 15.3$ & $67.8 \pm 14.1$ \\
\hline Standing (\% waking time) & $23.9 \pm 12.3$ & $22.3 \pm 11.6$ & $20.7 \pm 11.9$ & $21.4 \pm 8.8$ & $24.0 \pm 14.5$ & $20.7 \pm 12.6$ \\
\hline Sitting bouts > 30-min (\#) & $5.6 \pm 1.7$ & $6.2 \pm 2.2$ & $5.5 \pm 1.7$ & $6.1 \pm 1.7$ & $6.7 \pm 2.7 * \delta$ & $7.4 \pm 2.7$ \\
\hline Sitting bouts $>60-\min (\#)$ & $3.1 \pm 1.4$ & $3.1 \pm 1.5$ & $2.6 \pm 1.1$ & $3.1 \pm 1.6$ & $2.3 \pm 1.6$ & $2.8 \pm 2.0$ \\
\hline Step count $(\#)$ & $6409 \pm 2843$ & $7125 \pm 2554$ & $9376 \pm 2387^{* *}$ & $12,257 \pm 3149 * * *$ & $9250 \pm 2291 *$ & $10,036 \pm 4262 * * \delta \delta$ \\
\hline
\end{tabular}

Data are presented as the mean \pm SD. ${ }^{*} p<0.05,{ }^{* *} p<0.01,{ }^{* * *} p<0.0001$ compared to SED control within the same location. $\delta p<0.05, \delta \delta p<0.01$ different from ONE within same location. Sitting/lying $(\mathrm{h} / \mathrm{d})$, number of hours per day spent siting; Standing (h/d), number of hours per day spent standing; Stepping $(\mathrm{h} / \mathrm{d})$, number of hours per day spent standing; Sitting (\% waking time), percent of waking hours spent sitting; Standing (\% waking time), percent of waking hours spent sitting; Stepping (\% waking time), percent of waking hours spent stepping; Sitting bouts $>30$-min, number of sitting bouts lasting at least $30 \mathrm{~min}$; Sitting bouts $>60$-min, number of sitting bouts lasting at least $60 \mathrm{~min}$; Sit-to-stand transitions, number of times a participant rose from a seated position; Step Count (\#), is the number of steps taken per day.

\subsection{Effect of the Physical Activity Interventions on Time Spent in Very-Light, Light, Moderate and Vigorous} Intensity Physical Activity

Time spent in very-light, light, MVPA during waking hours is shown in Figure 2. One ActiGraph GT3X was lost; data are reported for 21 subjects.

On work days, waking time spent in very light intensity activities tended to be lower in ONE compared to SED $(12.5 \pm 1.3$ vs. $13.5 \pm 1.1 \mathrm{~h} / \mathrm{d}, p=0.055)$, but not different between MICRO and SED or ONE. Light intensity activities were not different across conditions $(p>0.05$ for all). On non-work days, MICRO significantly reduced time spent in light intensity activities compared to SED $(1.5 \pm 0.5$ vs. $1.9 \pm 0.8 \mathrm{~h} / \mathrm{d}, p=0.040)$, but was associated with more time spent in very light intensity activities than ONE $(13.7 \pm 0.5$ vs. $11.5 \pm 0.5 \mathrm{~h} / \mathrm{d}, p=0.002)$. Both MICRO (work day: $+23.4 \pm 6.6 \mathrm{~min}$, non-work day: $+21.6 \pm 8.4 \mathrm{~min}$ ) and ONE (work day: $+40.2 \pm 6.6$, non-work day: $+36.0 \pm 9.0 \mathrm{~min}$ ) significantly increased time spent in MVPA compared to SED on both non-work and work days ( $p<0.01$ for all). On work days, MVPA was even greater in ONE than in MICRO $(p=0.02)$. 

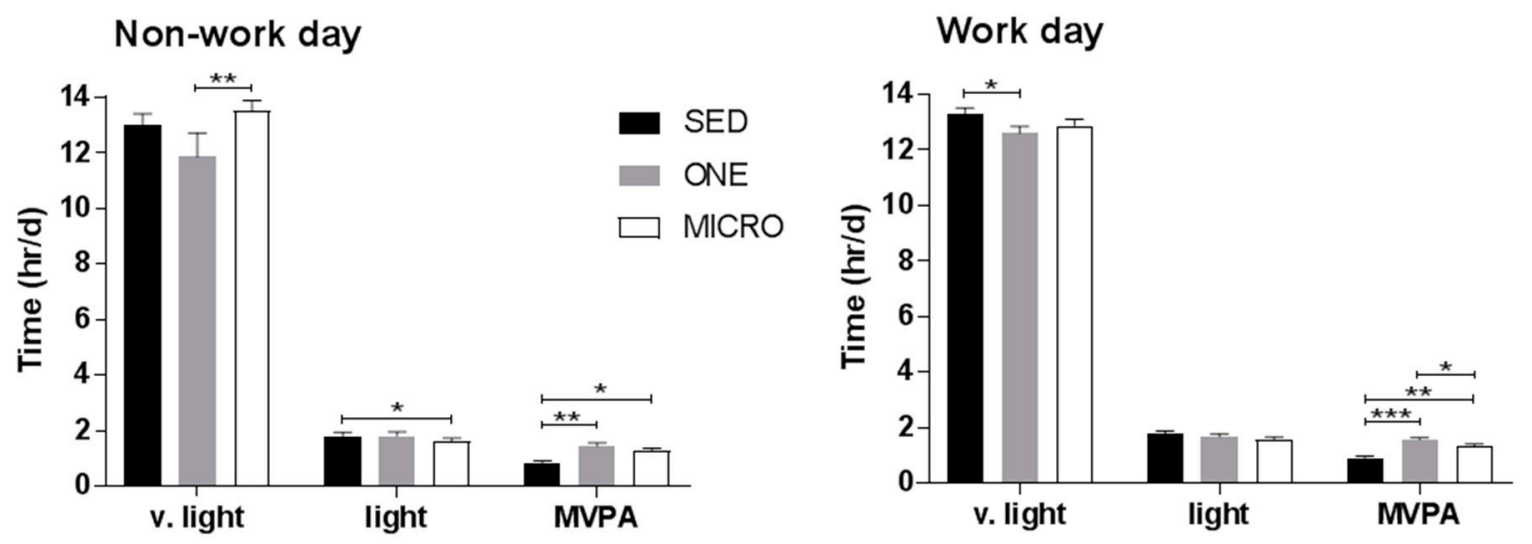

Figure 2. Waking time per day performing very light, light and moderate-to-vigorous intensity physical activity. Accelerometry data collected from ActiGraph GT3X tri-axial accelerometer are displayed by location (work or non-work day) and by physical activity intensity. V. light, very light intensity physical activity; MVPA, moderate-to-very vigorous intensity physical activity; SED, sedentary condition; ONE, one-bout intervention; MICRO, microbouts intervention. ${ }^{*} p<0.05,{ }^{* *} p<0.01,{ }^{* * *} p<0.0001$ vs. sedentary control condition.

\subsection{Effect of the Physical Activity Interventions on $24 \mathrm{~h}$ Activity Energy Expenditure and Physical} Activity Level

Changes in MVPA induced by the physical activity interventions translated into parallel changes in AEE (Figure 3). Both MICRO and ONE significantly increased AEE compared to SED on both work and non-work days ( $p<0.05$ for all). Physical activity level (PAL) was significantly lower in SED compared to ONE on non-work days (SED: $1.46 \pm 0.04$, ONE: $1.62 \pm 0.04, p=0.004$ ) and compared to both ONE and MICRO on work days (SED: $1.43 \pm 0.03$, ONE: $1.65 \pm 0.03, p<0.001$, MICRO: $1.55 \pm 0.03, p=0.003)$. PAL was further higher in ONE than in MICRO on work days $(p=0.008)$.

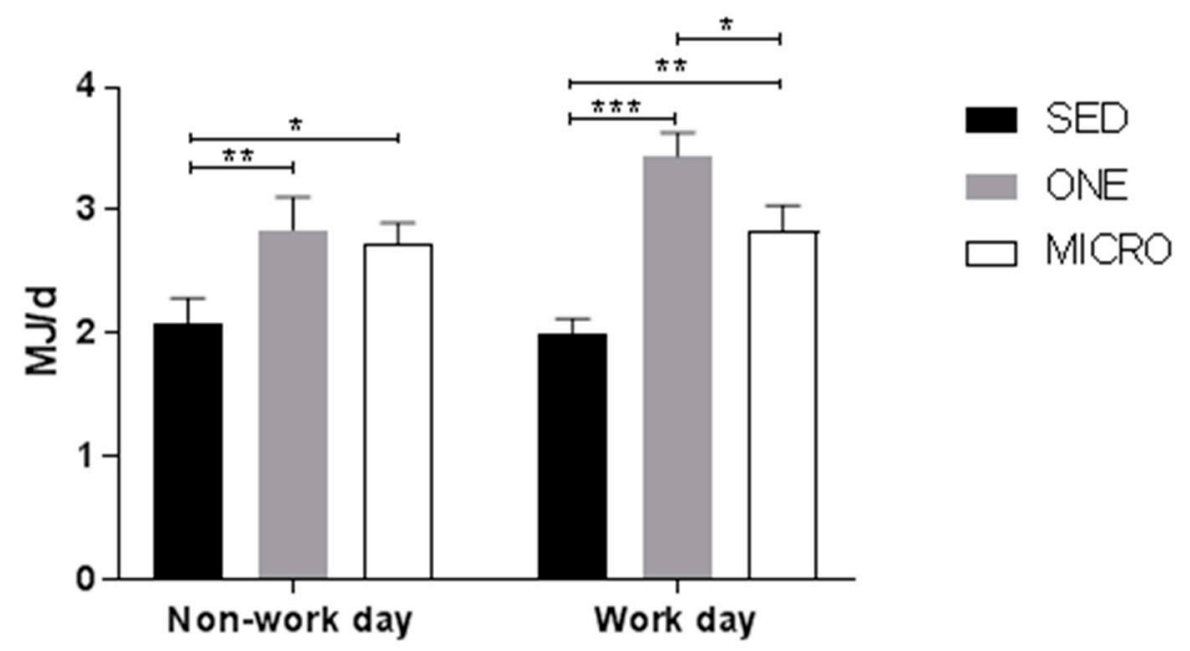

Figure 3. Activity energy expenditure. The activity energy expenditure (MJ/d) estimated from ActiGraph GT3X tri-axial accelerometer is displayed by location (work or non-work day). SED, sedentary condition; ONE, one-bout intervention; MICRO, microbouts intervention. ${ }^{*} p<0.05$, ${ }^{* *} p<0.01,{ }^{* * *} p<0.0001$ vs. sedentary control condition.

\subsection{Effect of the Physical Activity Interventions on Self-Perceived Vigor and Fatigue}

No significant differences in self-perceived vigor were noted across conditions on non-work days ( $p>0.05$ for all, Figure 4). On working days, participants reported a greater level of self-perceived vigor at the end of the day in both MICRO $(386.7 \pm 27.9, p=0.01)$ and ONE $(403.4 \pm 28.1, p=0.002)$ 
compared to SED (314.1 \pm 28.0$)$. They further reported feeling less fatigue on work days after a day performing MICRO than after a day performing ONE $(-119.7 \pm 52.5, p=0.03)$. On non-work days, they tended to feel less fatigue on MICRO compared to both SED $(-128.9 \pm 65.6, p=0.054)$ and ONE $(-124.5 \pm 67.3, p=0.069)$.
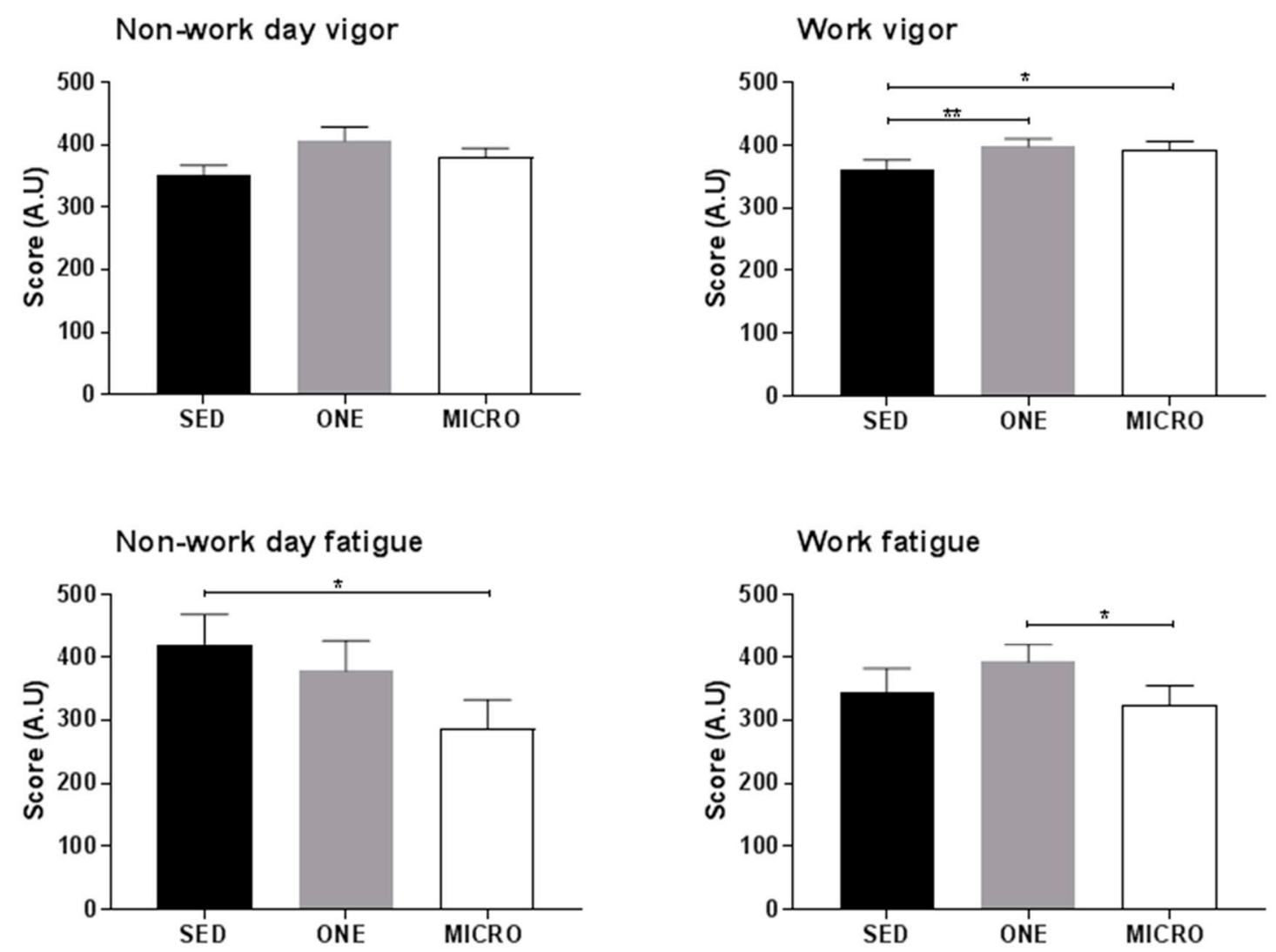

Figure 4. Self-perceived fatigue and vigor. At the end of each study day participants rated their self-perceived feeling of fatigue and vigor (arbitrary unit). SED, sedentary condition; ONE, one-bout intervention; MICRO, microbouts intervention. ${ }^{*} p<0.05,{ }^{* *} p<0.01$ vs. sedentary control condition.

3.6. Effect of the Physical Activity Interventions on Index of Insulin Sensitivity

On the morning of day 4, fasting insulin and glucose concentrations were measured (Table 3). MICRO and ONE significantly decreased fasting insulin concentration by $37.3 \%(p=0.03)$ and $43.6 \%$ $(p=0.02)$ respectively compared to SED. Fasting glucose concentrations remained unchanged. As a result, insulin:glucose ratio, an index of insulin sensitivity, was reduced by both MICRO $(p=0.03)$ and ONE $(p=0.02)$ compared to SED, suggesting an improvement in insulin sensitivity. No differences were observed between the two active conditions.

Table 3. Fasting plasma glucose and insulin concentrations.

\begin{tabular}{cccc}
\hline Parameters & SED & ONE & MICRO \\
\hline Fasting glucose $(\mathrm{mg} / \mathrm{dL})$ & $90.1 \pm 7.3$ & $88.4 \pm 7.7$ & $88.7 \pm 10.6$ \\
Fasting insulin $(\mathrm{uI} / \mathrm{mL})$ & $10.8 \pm 8.9$ & $6.1 \pm 3.0^{*}$ & $6.7 \pm 6.1 *$ \\
$\mathrm{I} / \mathrm{G}$ & $0.121 \pm 0.101$ & $0.069 \pm 0.341^{*}$ & $0.075 \pm 0.063 *$ \\
\hline
\end{tabular}

Data are presented as the mean \pm SD. ${ }^{*} p<0.05$ compared to SED control. I/G, insulin/glucose ratio.

\section{Discussion}

In this randomized feasibility study, we showed that sedentary, physically inactive, overweight/obese individuals were able to implement physical activity interventions consisting either of frequent bouts 
of activity or one continuous bout, the latter being more commonly promulgated by public health promotion initiatives and healthcare providers. Overall these two physical activity interventions had similar effects. Both interventions increased daily steps, MVPA, AEE and PAL on both working and non-working days compared to the sedentary control. These increases were more pronounced with a daily single bout of physical activity as compared to microbouts. The greater physical activity and energy expenditure were further associated with higher self-perceived feelings of vigor at the end of the day and improved fasting insulin sensitivity. Microbouts of activity were also associated with lower feelings of fatigue at the end of the day both on work days and non-work days. Neither of the interventions decreased time spent sitting or standing, the number of breaks from the sitting position and the average duration of a sitting bout.

Because office employees are vulnerable to the adverse health effects of prolonged sitting, an increasing number of interventions have targeted the work environment [54]. Strategies that promote body movements, such as passive pedaling or treadmill desks have been shown to increase physical activity and energy expenditure and to some extent reduce time spent sitting [18-20,25-27]. However, they are relatively expensive, can be a safety hazard and may be impractical to implement on a large scale. Therefore, we proposed that an intervention involving frequent short bouts of brisk walking could be an inexpensive, safe, easy to implement physical activity promotion intervention. Contrary to our hypothesis, microbouts of activity spread out across the day did not reduce the number or duration of sitting bouts and did not increase the number of transitions from the sitting position to standing or stepping. This may be because asking individuals to break-up prolonged sitting nine times a day, every hour for nine consecutive hours to perform 5-min of walking is not a sufficient stimulus. In support of this interpretation, a recent study used hourly computer screen prompts or text messages to break up sitting. Sitting time was broken up with $7 \mathrm{~min}$ of walking to accumulate 30-60 min of walking per day. Additionally, there was an additional 6000 step count goal. This intervention was 7 days measured in overweight/obese and resulted in a decrease in total sitting time by $1.85 \mathrm{~h} / \mathrm{d}$ on average [10]. Despite the frequency of activity being more frequent (every 30-60 min), this study also failed to show an increase in the number of sedentary breaks (sit-to-stand transitions) [10]. In our study, the number of sitting bouts longer than 30-min was even greater when participants were asked to perform microbouts of activity compared to single bouts on non-work days. This suggests that people tend to stay seated until they have to stand up and be active. Therefore, future studies may need to test specific interventions that primarily target breaks from sitting in addition to sitting time, daily steps or bouts of physical activity.

The American College of Sports Medicine, the American Heart Association and the American Diabetes Association recommend that adults perform at least 150-300 $\mathrm{min} / \mathrm{wk}$ (21.4-42.8 $\mathrm{min}$ /day) of MVPA to maintain and promote cardiovascular health and insulin sensitivity [55]. Implementing frequent short bouts of 5-min brisk walking across the day in our study led to a significant 22.5-min/day increase in MVPA on average. In addition, the microbouts intervention produced an increase in AEE of $0.54 \mathrm{MJ} / \mathrm{d}(129 \mathrm{kcal} / \mathrm{d})$ on non-working days and $0.78 \mathrm{MJ} / \mathrm{d}(187 \mathrm{kcal} / \mathrm{d})$ on work days. It has been proposed that a very small energy gap-the difference between energy intake and energy expenditure-plays a role in weight gain [56]. A difference of $100 \mathrm{kcal} /$ day at the population level could theoretically prevent weight gain in $90 \%$ of the U.S. adult population. Consequently, the increase in AEE along with the suppressive effect on appetite previously reported with microbouts of activity (at least in normal-weight individuals) $[27,30]$ may help mitigate weight gain. Implementing microbouts of activity at work could be a viable strategy, among other strategies, to slow down weight gain. In addition, large prospective cohort studies of diverse populations have shown that an AEE of approximately $4.18 \mathrm{MJ} / \mathrm{wk}(1000 \mathrm{kcal} / \mathrm{wk})$ is associated with lower rates of cardiovascular disease and premature mortality [55]. It would therefore be important to study the effect of this intervention over the long-term and verify whether a $1000 \mathrm{kcal} / \mathrm{wk}$ energy expenditure could be reached. Finally, our feasibility study showed that three days of microbouts of activity performed in daily life improves insulin sensitivity, which adds to the increasing body of data collected in the 
laboratory settings on the beneficial effect of frequent interruptions of prolonged sitting on insulin action [31-40,57]. This is the first study to show that an intervention using small bouts of activity promotes overweight-obese sedentary adults to comply with the current physical activity guidelines, at least in the short term. As a result, this strategy may have positive effects on body weight control and cardiometabolic health. However, we need to acknowledge that the single bout intervention we tested in the same subjects induced greater increases in MVPA (40 min/work day) and AEE 1.41 MJ/work day (+337 kcal/work day). The subjects thus attained a PAL of 1.65 that is characteristic of people who are moderately active. Future studies are needed to test the long-term effects of the microbouts of activity versus single bout of activity on the daily pattern of physical activity and energy balance regulation (appetite, energy intake, energy expenditure).

The long-term goal will be to test this type of intervention in the public on a large scale. The modern occupational environment promotes increased sedentary time [58], and has therefore been identified as an ideal environment to target sedentary behaviors. This is even more important because adults who spend more time sedentary at work do not compensate by being more active during non-working periods [59]. Interestingly, we showed that the beneficial effects of the microbouts intervention on physical activity and self-perceived fatigue were observed on both work and non-work days. This means that if implemented in occupational contexts this intervention, if sustained on weekends, could also increase physical activity on non-work days. A limitation is that instead of shifting time from very light to MVPA intensity activities as observed with the single bout of activity, the microbouts of activity increased MVPA in detriment of light intensity activity on non-work days. Another potential issue for future implementation of such intervention is the fact that participants reported the microbouts of activity to be more challenging to perform at work. But in our study, participants were the only employees performing these activities at their workplace. If the environment was designed to support breaking up sitting, participants may find this approach less challenging. It is well known that socio-ecological approaches acting on both the micro environment (individual) and macro environment (socio-professional environment, office layout, alternative work stations, active vs. sitting meetings, etc.) are key when aiming to implement new interventions that change behavior for a sustained period of time. Developing strategies to self-motivate individuals in adopting this new behavior is also crucial [60]. The fact that our overweight/obese participants perceived less fatigue at the end of a workday performing the microbouts than a single continuous bout of activity, as we previously reported in normal weight individuals, could be used to encourage employers to incorporate microbouts of activity into the daily routines of their office employees [30]. Additionally, strategies aiming to reduce time spent sitting have not been shown to affect productivity or cognitive functions [28-30]. Most likely, a combination of the two interventions to target both occupational and non-work time may be the best approach. It could also provide individuals with different tools to choose from according to their mood that day at the office or outside the office.

Several limitations need to be acknowledged. The main limitation is that the study was conducted over 3-days and so conclusions about whether the weekly level of recommended MVPA could be reached and sustained for longer time periods cannot be made. The comparison between work days and non-work days was not a priori powered and led to an unbalanced number of days spent in the two different settings. Because participant's knew their physical activity was being tracked by two physical activity monitors there could have been an effect of increased activity [61]. Indeed Clemes et al. showed that wearing activity monitors for three days induces a spike in physical activity levels that regresses back to the mean after 7-days [61]. However, other studies have shown no evidence of reactivity to physical activity monitors [62,63]. In addition, the cross-over design may have limited the reactivity effect to the monitors. Another strength was that the pattern of physical activities was assessed using two complementary activity monitors, one specifically designed to detect changes in sitting and the other one designed to determine time spent in activities of different intensities and the associated energy expenditure. Finally, this feasibility study testing a novel lifestyle intervention to 
prevent sedentary behavior was conducted in overweight/obese, sedentary, physically inactive adults, which represent a high-risk group for metabolic diseases.

\section{Conclusions}

This feasibility study showed in overweight/obese physically inactive sedentary adults that regardless of the terms of the intervention, promoting physical activity led to an increase in physical activity and energy expenditure, and improved insulin sensitivity and vigor. However, none reduced total daily sitting time or the length of sitting bouts. This suggests that more efforts are needed in the workplace to increase physical activity along with a concomitant reduction in the number and duration of sitting bouts. It may be that frequent prompts to rise from sitting in combination with encouragements for either microbouts or single bouts of activity may represent the best overall strategy. This will need to be tested as part of a multicomponent intervention at the organizational, environmental and individual levels. Therefore, the overall public health message should communicate that any increase in physical activity can be beneficial when performed consistently over time.

Author Contributions: A.B. and D.H.B. designed the study, collected, analyzed and interpreted data, and drafted the manuscript. N.P.D.J. collected, analyzed and interpreted data, and drafted the manuscript. I.D., M.G., K.L., C.S. (Cédric Sueur), C.S. (Chantal Simon) analyzed and interpreted data and drafted the manuscript. Z.P. performed statistical analysis and drafted the manuscript. All authors gave final approval of the manuscript to be published and agreed to be accountable for all aspects of the work in ensuring that questions related to the accuracy or integrity of any part of the work are appropriately investigated and resolved.

Funding: This work was supported by the National Institutes of Health grant numbers K99DK100465 (A.B.) and UL1 TR001082 (A.B.), NORC 5P30DK048520 (A.B., D.H.B.), CTRC UL1TR002535 (A.B., D.H.B.), 5P30DK048520 (Z.P.). This publication was also supported by Grant Number T42OH009229-10 (A.B.) from CDC NIOSH Mountain and Plains Education and Research Center. C.S. (Cédric Sueur) and I.D. are funded by a grant from the French national Research Agency (ANR-15-CE36-0005) and by the Grand Est Region (France). The contents of this publication are solely the responsibility of the authors and do not necessarily represent the official views of the funding sources.

Acknowledgments: The authors thank study volunteers for their time and participation. They are also very thankful for the University of Colorado Hospital CTRC staff.

Conflicts of Interest: The authors declare no conflict of interest. The funding sponsors had no role in the design of the study; in the collection, analyses, or interpretation of data; in the writing of the manuscript, and in the decision to publish the results.

\section{References}

1. Owen, N.; Healy, G.N.; Matthews, C.E.; Dunstan, D.W. Too Much Sitting: The Population-Health Science of Sedentary Behavior. Exerc. Sport Sci. Rev. 2010, 38, 105-113. [CrossRef] [PubMed]

2. Bauman, A.E.; Chau, J.Y.; Ding, D.; Bennie, J. Too Much Sitting and Cardio-Metabolic Risk: An Update of Epidemiological Evidence. Curr. Cardiovasc. Risk Rep. 2013, 7, 293-298. [CrossRef]

3. Thorp, A.A.; Owen, N.; Neuhaus, M.; Dunstan, D.W. Sedentary behaviors and subsequent health outcomes in adults a systematic review of longitudinal studies, 1996-2011. Am. J. Prev. Med. 2011, 41, $207-215$. [CrossRef] [PubMed]

4. Wilmot, E.G.; Edwardson, C.L.; Achana, F.A.; Davies, M.J.; Gorely, T.; Gray, L.J.; Khunti, K.; Yates, T.; Biddle, S.J. Sedentary time in adults and the association with diabetes, cardiovascular disease and death: Systematic review and meta-analysis. Diabetologia 2012, 55, 2895-2905. [CrossRef] [PubMed]

5. Edwardson, C.L.; Gorely, T.; Davies, M.J.; Gray, L.J.; Khunti, K.; Wilmot, E.G.; Yates, T.; Biddle, S.J. Association of sedentary behaviour with metabolic syndrome: A meta-analysis. PLoS ONE 2012, 7, e34916. [CrossRef] [PubMed]

6. $\quad$ de Rezende, L.F.; Rodrigues Lopes, M.; Rey-Lopez, J.P.; Matsudo, V.K.; Luiz Odo, C. Sedentary behavior and health outcomes: An overview of systematic reviews. PLoS ONE 2014, 9, e105620. [CrossRef] [PubMed]

7. Suchert, V.; Hanewinkel, R.; Isensee, B. Sedentary behavior and indicators of mental health in school-aged children and adolescents: A systematic review. Prev. Med. 2015, 76, 48-57. [CrossRef] [PubMed] 
8. van Uffelen, J.G.; van Gellecum, Y.R.; Burton, N.W.; Peeters, G.; Heesch, K.C.; Brown, W.J. Sitting-time, physical activity, and depressive symptoms in mid-aged women. Am. J. Prev. Med. 2013, 45, 276-281. [CrossRef] [PubMed]

9. Rynders, C.A.; Blanc, S.; DeJong, N.; Bessesen, D.H.; Bergouignan, A. Sedentary behaviour is a key determinant of metabolic inflexibility. J. Physiol. 2017, 596, 1319-1330. [CrossRef] [PubMed]

10. Judice, P.B.; Hamilton, M.T.; Sardinha, L.B.; Silva, A.M. Randomized controlled pilot of an intervention to reduce and break-up overweight/obese adults' overall sitting-time. Trials 2015, 16, 490. [CrossRef] [PubMed]

11. Healy, G.N.; Dunstan, D.W.; Salmon, J.; Cerin, E.; Shaw, J.E.; Zimmet, P.Z.; Owen, N. Breaks in sedentary time: Beneficial associations with metabolic risk. Diabetes Care 2008, 31, 661-666. [CrossRef] [PubMed]

12. Healy, G.N.; Matthews, C.E.; Dunstan, D.W.; Winkler, E.A.; Owen, N. Sedentary time and cardio-metabolic biomarkers in US adults: NHANES 2003-06. Eur. Heart J. 2011, 32, 590-597. [CrossRef] [PubMed]

13. McCrady, S.K.; Levine, J.A. Sedentariness at Work: How Much Do We Really Sit? Obesity 2009, 17, $2103-2105$. [CrossRef] [PubMed]

14. Ryan, C.G.; Dall, P.M.; Granat, M.H.; Grant, P.M. Sitting patterns at work: Objective measurement of adherence to current recommendations. Ergonomics 2011, 54, 531-538. [CrossRef]

15. Church, T.S.; Thomas, D.M.; Tudor-Locke, C.; Katzmarzyk, P.T.; Earnest, C.P.; Rodarte, R.Q.; Martin, C.K.; Blair, S.N.; Bouchard, C. Trends over 5 decades in U.S. occupation-related physical activity and their associations with obesity. PLoS ONE 2011, 6, e19657. [CrossRef] [PubMed]

16. Physical Activity Strategy for the WHO European Region. Available online: http://www.euro. who.int/_data/assets/pdf_file/0010/282961/65wd09e_PhysicalActivityStrategy_150474.pdf (accessed on 30 August 2018).

17. Alkhajah, T.A.; Reeves, M.M.; Eakin, E.G.; Winkler, E.A.H.; Owen, N.; Healy, G.N. Sit-Stand Workstations: A Pilot Intervention to Reduce Office Sitting Time. Am. J. Prev. Med. 2012, 43, 298-303. [CrossRef] [PubMed]

18. Carr, L.J.; Walaska, K.A.; Marcus, B.H. Feasibility of a portable pedal exercise machine for reducing sedentary time in the workplace. Br. J. Sports Med. 2012, 46, 430-435. [CrossRef] [PubMed]

19. Jones, R.A.; Hinkley, T.; Okely, A.D.; Salmon, J. Tracking physical activity and sedentary behavior in childhood: A systematic review. Am. J. Prev. Med. 2013, 44, 651-658. [CrossRef] [PubMed]

20. Gilson, N.D.; Suppini, A.; Ryde, G.C.; Brown, H.E.; Brown, W.J. Does the use of standing 'hot' desks change sedentary work time in an open plan office? Prev. Med. 2012, 54, 65-67. [CrossRef] [PubMed]

21. Healy, G.N.; Eakin, E.G.; Owen, N.; Lamontagne, A.D.; Moodie, M.; Winkler, E.A.; Fjeldsoe, B.S.; Wiesner, G.; Willenberg, L.; Dunstan, D.W. A Cluster Randomized Controlled Trial to Reduce Office Workers' Sitting Time: Effect on Activity Outcomes. Med. Sci. Sports Exerc. 2016, 48, 1787-1797. [CrossRef] [PubMed]

22. Hutchinson, J.; Headley, S.; Matthews, T.; Spicer, G.; Dempsey, K.; Wooley, S.; Janssen, X. Changes in Sitting Time and Sitting Fragmentation after a Workplace Sedentary Behaviour Intervention. Int. J. Environ. Res. Public Health 2018, 15, 1148. [CrossRef] [PubMed]

23. Evans, R.E.; Fawole, H.O.; Sheriff, S.A.; Dall, P.M.; Grant, P.M.; Ryan, C.G. Point-of-choice prompts to reduce sitting time at work: A randomized trial. Am. J. Prev. Med. 2012, 43, 293-297. [CrossRef] [PubMed]

24. Carr, L.J.; Karvinen, K.; Peavler, M.; Smith, R.; Cangelosi, K. Multicomponent intervention to reduce daily sedentary time: A randomised controlled trial. BMJ Open 2013, 3, e003261. [CrossRef] [PubMed]

25. Koepp, G.A.; Manohar, C.U.; McCrady-Spitzer, S.K.; Ben-Ner, A.; Hamann, D.J.; Runge, C.F.; Levine, J.A. Treadmill desks: A 1-year prospective trial. Obesity 2013, 21, 705-711. [CrossRef] [PubMed]

26. Tudor-Locke, C.; Schuna, J.M., Jr.; Frensham, L.J.; Proenca, M. Changing the way we work: Elevating energy expenditure with workstation alternatives. Int. J. Obes. 2014, 38, 755-765. [CrossRef] [PubMed]

27. Levine, J.A.; Miller, J.M. The energy expenditure of using a "walk-and-work" desk for office workers with obesity. Br. J. Sports Med. 2007, 41, 558. [CrossRef] [PubMed]

28. Wennberg, P.; Boraxbekk, C.-J.; Wheeler, M.; Howard, B.; Dempsey, P.C.; Lambert, G.; Eikelis, N.; Larsen, R.; Sethi, P.; Occleston, J.; et al. Acute effects of breaking up prolonged sitting on fatigue and cognition: A pilot study. BMJ Open 2016, 6, e009630. [CrossRef] [PubMed]

29. Thorp, A.A.; Kingwell, B.A.; Owen, N.; Dunstan, D.W. Breaking up workplace sitting time with intermittent standing bouts improves fatigue and musculoskeletal discomfort in overweight/obese office workers. Occup. Environ. Med. 2014, 71, 765-771. [CrossRef] [PubMed]

30. Bergouignan, A.; Legget, K.T.; De Jong, N.; Kealey, E.; Nikolovski, J.; Groppel, J.L.; Jordan, C.; O’Day, R.; Hill, J.O.; Bessesen, D.H. Effect of frequent interruptions of prolonged sitting on self-perceived levels of 
energy, mood, food cravings and cognitive function. Int. J. Behav. Nutr. Phys. Act. 2016, 13, 113. [CrossRef] [PubMed]

31. Dunstan, D.W.; Kingwell, B.A.; Larsen, R.; Healy, G.N.; Cerin, E.; Hamilton, M.T.; Shaw, J.E.; Bertovic, D.A.; Zimmet, P.Z.; Salmon, J.; et al. Breaking Up Prolonged Sitting Reduces Postprandial Glucose and Insulin Responses. Diabetes Care 2012, 35, 976-983. [CrossRef] [PubMed]

32. Peddie, M.C.; Bone, J.L.; Rehrer, N.J.; Skeaff, C.M.; Gray, A.R.; Perry, T.L. Breaking prolonged sitting reduces postprandial glycemia in healthy, normal-weight adults: A randomized crossover trial. Am. J. Clin. Nutr. 2013, 98, 358-366. [CrossRef] [PubMed]

33. van Dijk, J.W.; Venema, M.; van Mechelen, W.; Stehouwer, C.D.; Hartgens, F.; van Loon, L.J. Effect of moderate-intensity exercise versus activities of daily living on 24-hour blood glucose homeostasis in male patients with type 2 diabetes. Diabetes Care 2013, 36, 3448-3453. [CrossRef] [PubMed]

34. Blankenship, J.M.; Granados, K.; Braun, B. Effects of subtracting sitting versus adding exercise on glycemic control and variability in sedentary office workers. Appl. Physiol. Nutr. Metab. 2014, 39, 1286-1293. [CrossRef] [PubMed]

35. Buckley, J.P.; Mellor, D.D.; Morris, M.; Joseph, F. Standing-based office work shows encouraging signs of attenuating post-prandial glycaemic excursion. Occup. Environ. Med. 2014, 71, 109-111. [CrossRef] [PubMed]

36. Holmstrup, M.; Fairchild, T.; Keslacy, S.; Weinstock, R.; Kanaley, J. Multiple short bouts of exercise over 12-h period reduce glucose excursions more than an energy-matched single bout of exercise. Metab. Clin. Exp. 2014, 63, 510-519. [CrossRef] [PubMed]

37. Bailey, D.P.; Locke, C.D. Breaking up prolonged sitting with light-intensity walking improves postprandial glycemia, but breaking up sitting with standing does not. J. Sci. Med. Sport 2015, 18, 294-298. [CrossRef] [PubMed]

38. Larsen, R.N.; Kingwell, B.A.; Robinson, C.; Hammond, L.; Cerin, E.; Shaw, J.E.; Healy, G.N.; Hamilton, M.T.; Owen, N.; Dunstan, D.W. Breaking up of prolonged sitting over three days sustains, but does not enhance, lowering of postprandial plasma glucose and insulin in overweight and obese adults. Clin. Sci. 2015, 129, 117-127. [CrossRef] [PubMed]

39. Dempsey, P.C.; Blankenship, J.M.; Larsen, R.N.; Sacre, J.W.; Sethi, P.; Straznicky, N.E.; Cohen, N.D.; Cerin, E.; Lambert, G.W.; Owen, N.; et al. Interrupting prolonged sitting in type 2 diabetes: Nocturnal persistence of improved glycaemic control. Diabetologia 2017, 60, 499-507. [CrossRef] [PubMed]

40. Dempsey, P.C.; Larsen, R.N.; Sethi, P.; Sacre, J.W.; Straznicky, N.E.; Cohen, N.D.; Cerin, E.; Lambert, G.W.; Owen, N.; Kingwell, B.A.; et al. Benefits for Type 2 Diabetes of Interrupting Prolonged Sitting With Brief Bouts of Light Walking or Simple Resistance Activities. Diabetes Care 2016, 39, 964-972. [CrossRef] [PubMed]

41. Hadgraft, N.T.; Lynch, B.M.; Clark, B.K.; Healy, G.N.; Owen, N.; Dunstan, D.W. Excessive sitting at work and at home: Correlates of occupational sitting and TV viewing time in working adults. BMC Public Health 2015, 15, 899. [CrossRef] [PubMed]

42. Kim, J.; Shin, W. How to Do Random Allocation (Randomization). Clin. Orthop. Surg. 2014, 6, 103-109. [CrossRef] [PubMed]

43. Booth, M. Assessment of physical activity: An international perspective. Res. Q. Exerc. Sport 2000, 71, 114-120. [CrossRef] [PubMed]

44. Grant, P.M.; Ryan, C.G.; Tigbe, W.W.; Granat, M.H. The validation of a novel activity monitor in the measurement of posture and motion during everyday activities. Br. J. Sports Med. 2006, 40, 992-997. [CrossRef] [PubMed]

45. Godfrey, A.; Culhane, K.M.; Lyons, G.M. Comparison of the performance of the activPAL Professional physical activity logger to a discrete accelerometer-based activity monitor. Med. Eng. Phys. 2007, 29, 930-934. [CrossRef] [PubMed]

46. Kozey-Keadle, S.; Libertine, A.; Lyden, K.; Staudenmayer, J.; Freedson, P.S. Validation of wearable monitors for assessing sedentary behavior. Med. Sci. Sports Exerc. 2011, 43, 1561-1567. [CrossRef] [PubMed]

47. Ryan, C.G.; Grant, P.M.; Tigbe, W.W.; Granat, M.H. The validity and reliability of a novel activity monitor as a measure of walking. Br. J. Sports Med. 2006, 40, 779-784. [CrossRef] [PubMed]

48. Zhang, Y.; Li, H.; Keadle, S.; Matthews, C.E.; Carroll, R. PAactivPAL: Summarize Daily Physical Activity from 'activPAL' Accelerometer Data. Available online: https://rdrr.io/cran/PAactivPAL/ (accessed on 31 August 2018). 
49. Actigraph Support Center. What Is the Difference among the Energy Expenditure Algorithms? Available online: https:/ / actigraph.desk.com/customer/en/portal/articles/2515835-what-is-the-difference-amongthe-energy-expenditure-algorithms- (accessed on 5 May 2018).

50. Sasaki, J.E.; John, D.; Freedson, P.S. Validation and comparison of ActiGraph activity monitors. J. Sci. Med. Sport 2011, 14, 411-416. [CrossRef] [PubMed]

51. Tremblay, M.S.; Aubert, S.; Barnes, J.D.; Saunders, T.J.; Carson, V.; Latimer-Cheung, A.E.; Chastin, S.F.M.; Altenburg, T.M.; Chinapaw, M.J.M.; Altenburg, T.M.; et al. Sedentary Behavior Research Network (SBRN)-Terminology Consensus Project process and outcome. Int. J. Behav. Nutr. Phys. Act. 2017, 14, 75. [CrossRef] [PubMed]

52. Reips, U.D.; Funke, F. Interval-level measurement with visual analogue scales in Internet-based research: VAS Generator. Behav. Res. Methods 2008, 40, 699-704. [CrossRef] [PubMed]

53. McNair, D.M.; Lorr, M.; Droppleman, L.F. Manual Profile of Mood States; Educational \& Industrial Testing Service: San Diego, CA, USA, 1971.

54. Parry, S.; Straker, L. The contribution of office work to sedentary behaviour associated risk. BMC Public Health 2013, 13, 296. [CrossRef] [PubMed]

55. Haskell, W.L.; Lee, I.M.; Pate, R.R.; Powell, K.E.; Blair, S.N.; Franklin, B.A.; Macera, C.A.; Heath, G.W.; Thompson, P.D.; Bauman, A. Physical activity and public health: Updated recommendation for adults from the American College of Sports Medicine and the American Heart Association. Med. Sci. Sports Exerc. 2007, 39, 1423-1434. [CrossRef] [PubMed]

56. Hill, J.O. Understanding and addressing the epidemic of obesity: An energy balance perspective. Endocr. Rev. 2006, 27, 750-761. [CrossRef] [PubMed]

57. Bergouignan, A.; Latouche, C.; Heywood, S.; Grace, M.S.; Reddy-Luthmoodoo, M.; Natoli, A.K.; Owen, N.; Dunstan, D.W.; Kingwell, B.A. Frequent interruptions of sedentary time modulates contraction- and insulin-stimulated glucose uptake pathways in muscle: Ancillary analysis from randomized clinical trials. Sci. Rep. 2016, 6, 32044. [CrossRef] [PubMed]

58. Black, A.E. Physical activity levels from a meta-analysis of doubly labeled water studies for validating energy intake as measured by dietary assessment. Nutr. Rev. 1996, 54, 170-174. [CrossRef] [PubMed]

59. Clemes, S.A.; O'Connell, S.E.; Edwardson, C.L. Office workers' objectively measured sedentary behavior and physical activity during and outside working hours. J. Occup. Environ. Med. 2014, 56, 298-303. [CrossRef] [PubMed]

60. Bessesen, D.; Bergouignan, A. Behavior Change Strategies for Increasing Exercise and Decreasing Sedentary Behaviors in Diabetes. In Diabetes and Exercise: From Pathophysiology to Clinical Implementation; Reusch, J.E.B., Regensteiner, J.G., Stewart, K.J., Veves, A., Eds.; Springer International Publishing: Cham, Switzerland, 2018; pp. 201-219.

61. Clemes, S.A.; Parker, R.A. Increasing our understanding of reactivity to pedometers in adults. Med. Sci. Sports Exerc. 2009, 41, 674-680. [CrossRef] [PubMed]

62. Behrens, T.K.; Dinger, M.K. Motion sensor reactivity in physically active young adults. Res. Q. Exerc. Sport 2007, 78, 1-8. [CrossRef] [PubMed]

63. Davis, R.E.; Loprinzi, P.D. Examination of Accelerometer Reactivity among a Population Sample of Children, Adolescents, and Adults. J. Phys. Act. Health 2016, 13, 1325-1332. [CrossRef] [PubMed]

(C) 2018 by the authors. Licensee MDPI, Basel, Switzerland. This article is an open access article distributed under the terms and conditions of the Creative Commons Attribution (CC BY) license (http://creativecommons.org/licenses/by/4.0/). 